\title{
Análisis y propuesta de herramientas digitales aplicadas en la mercadotecnia en las medianas empresas de Servicios Restauranteras
}

\section{Analysis and proposal of digital tools applied in the marketing in the Restaurant Services companies}

GAZCA-HERRERA, Luis Alejandro $\dagger^{*}$, VALDEZ-MÉNDEZ, Alejandro, CULEBRO-CASTILLO, Karina y ALVAREZ-LOYA, Yamilet Sadaí

Universidad Veracruzana

ID 1 ${ }^{\mathrm{er}}$ Autor: Luis Alejandro, Gazca-Herrera / ORC ID: 0000-0001-7637-2909, CVU CONACYT ID: 105089

ID $1^{\text {er }}$ Coautor: Alejandro, Valdez-Méndez / ORC ID: 0000-0002-7303-0265, CVU CONACYT ID: 9866383

ID $2^{\text {do }}$ Coautor: Karina, Culebro-Castillo / ORC ID: 0000-0001-8443-1884

ID $3^{\text {er }}$ Coautor: Yamilet Sadaí, Alvarez-Loya / ORC ID: 0000-0001-7562-6209

DOI: $10.35429 / J U S D .2019 .15 .5 .13-23$

Recibido: 30 de Julio, 2019; Aceptado 20 de Septiembre, 2019

\begin{abstract}
Resumen
Las herramientas digitales (HD) hoy día se han vuelto indispensables en el ámbito empresarial, el crecimiento del país tiene una referencia directa con la creación y fortalecimiento de la MPyMES, siendo el sector de los servicios de mucha presencia en los mercados locales, y los restaurantes al ser empresa de utilidades confiables suelen consolidarse como un negocio formal, al identificar estos aspectos, se decidió realizar esta investigación con el objetivo en primera instancia de obtener datos sobre el diagnóstico en el uso de las HD , para lo cual se destaca un aspecto metodológico desde la parte conceptual y teórica permitiendo llevar a cabo la conceptualización, bajo un proceso deductivo, llevando a cabo el proceso de conceptualización al de operacionalización siguiendo las fases de representación teórica y especificación del concepto, para la identificación de las dimensiones y de éstos sus indicadores, dando como resultado un instrumento con validez y confiabilidad que se aplicó a una muestra, para que, con base en el diagnóstico y como segunda instancia se hiciera la propuesta del uso de HD para mejorar los aspectos mercadológicos en beneficio de la consolidación de este tipo de empresas.
\end{abstract}

Herramientas digitales, Mercadotecnia, Restaurantes

\begin{abstract}
Digital tools (DT) today have become indispensable in the business world, the growth of the country has a direct reference to the creation and strengthening of the MPyMES, with the services sector having a strong presence in local markets and restaurants Being a company of reliable utilities usually consolidate as a formal business, when identifying these aspects, it was decided to carry out this research with the objective in the first instance of obtaining data on the diagnosis in the use of DT, for which a methodological aspect is highlighted from the conceptual and theoretical part allowing to carry out the conceptualization, under a deductive process, carrying out the process of conceptualization to operationalization following the phases of theoretical representation of the concept, specification of the concept for the identification of the dimensions and of each dimension its indicators, resulting in an instrument was done with validity and reliability that was applied to a sample so that, based on the diagnosis and as a second instance, the proposal of the use of DT would be made to improve the marketing aspects in benefit of the consolidation of this type of companies.
\end{abstract}

Digital tools, Marketing, Restaurants

Citación: GAZCA-HERRERA, Luis Alejandro, VALDEZ-MÉNDEZ, Alejandro, CULEBRO-CASTILLO, Karina y ALVAREZ-LOYA, Yamilet Sadaí. Análisis y propuesta de herramientas digitales aplicadas en la mercadotecnia en las medianas empresas de Servicios Restauranteras. Revista del Desarrollo Urbano y Sustentable. 2019. 5-15: 13-23

*Correspondencia al autor (Correo electrónico: lgazca@uv.mx)

$\dagger$ Investigador contribuyendo como primer autor 


\section{Introducción}

En esta investigación se presentan los resultados de un diagnóstico sobre las herramientas digitales (HD) aplicadas a la mercadotecnia en las medianas empresas de servicios restauranteras de la Ciudad de Xalapa Veracruz y la región, tuvo como objetivo llevar a cabo un análisis para identificar de qué forma son aplicadas las HD y la importancia que este tipo de organizaciones dan al ámbito tecnológico; en el mismo sentido y posterior al análisis realizado, se hace una propuesta de HD que apoyen a las actividades de la mercadotecnia para consolidar su operatividad; es fundamental destacar que en la actualidad las HD han impactado en el ámbito de la mercadotecnia en todo tipo de organizaciones, al implementar estas estrategias les han permitido destacar en el mercado y claramente les ayudan a posicionarse en el mismo para tener una mayor interacción con los clientes.

En cuanto a la investigación se considera de tipo exploratorio, con un enfoque mixto, bajo un paradigma positivista no experimental. Exploratoria dado que no se ha realizado una investigación que determine el impacto de las HD en las empresas restauranteras en el ámbito de la mercadotécnica, asimismo, se considera de tipo descriptivo, es decir, únicamente se pretende medir o recoger información de manera independiente o conjunta sobre los conceptos o las variables a las que se refieren. El objetivo no es indicar cómo se relacionan las variables mediante un estudio correlacional, sino sólo identificar qué impacto tiene las HD en su conjunto.

En cuanto al aspecto metodológico en primer término se consideró el proceso de conceptualización que permitiera obtener toda la base teórica para posteriormente realizar la operaciónalizacion identificando la variable, las dimensiones, los indicadores y finalmente los ítems que conformaron el instrumento que se aplicaría a las empresas antes mencionadas; en segundo término se realizó el proceso de validez y confiabilidad del instrumento, por lo que se llevó a juicio de expertos aplicando a los resultados de cada juez la metodología de Kappa de Fleiss para determinar el grado de concordancia de cada uno de ellos, resultando favourable.
Posteriormente a una prueba piloto del instrumento se le aplicó el Alpha de Cronbach para medir la fiabilidad del instrumento el cual nuevamente resulto con resultados favorables por lo que se contó un un instrumento viable y confiable.

Al contar con un intrumento con las características antes mencionadas se realizó el cálculo de la muestra para finalmente con base en los resultados y con la aplicación SPSS se comprobó la hipótesis en el sentido de que las empresas en cuestión no hacen uso de las HD, desaprovechando una oportunidad para poder consolidarse en el sector restaurantero.

La aportación de esta investigación se enfoca en que, con base, en la metodología llevada a cabo se puede realizar un análisis en otros tipos de municipios con un carácter turístico que pueda proporcionar información fiable para establecer mecanismos de implementación de la tecnología que beneficie a este sector consolidándolo a nivel regional y nacional.

\section{Marco conceptual}

La mediana empresa tiene suma relevancia en el sector restaurantero de la ciudad de Xalapa y su región, así como en México en general, ha sido parte importante para su crecimiento. Es por ello, que es relevante el estudio de sus elementos que lo conforman para generar el crecimiento y consolidación de este tipo de empresas, uno de esos elementos específicamente es el análisis de las herramientas digitales que utilizan en el ámbito de la mercadotecnia.

Un aspecto significativo en el ámbito de la tecnología es la mercadotecnia digital, Gutiérrez (2016) citando a (Chaffey y Smith, 2013) nos dice que la mercadotecnia digital, mercadotecnia de Internet o mercadotecnia electrónica, que se requiere al uso de las TIC en la práctica mercadológica, es clave para los negocios, ya que permite acercarse a los clientes, entenderlos mejor, agregar valor a los productos, aumentar los canales de distribución e impulsar las ventas. 
Sin embargo Gutiérrez (2016) argumenta que, en las pequeñas y medianas empresas (PYMES), la mercadotecnia digital apenas se vislumbra como una alternativa clave, ya que tienen características particulares que ayudan a su mayor flexibidad, pero también obstaculizan en el desarrollo de una visión estratégica, y él mismo menciona y cita sobre estudios como el de Apak y Etai (2014), explica que las PYMES tienen ventaja con respecto a las grandes empresas dada por su estructura y adaptabilidad, ya que las implementaciones se desarrollan de manera más flexibe (Nada, 2010), el acercamiento del personal estimula el conocimiento compartido y nuevos procesos se dan a la par junto con el aprendizaje organizacional (Sparrow, 2001).

Kiinteroo (2017) menciona que como herramientas digitales se pueden definir aquellos software o programas intangibles que se encuentran en las computadoras $o$ dispositivos computacionales, donde se le da uso y se realiza todo tipo de actividades y, una de las grandes ventajas que tienen el manejo de estas herramientas, es que pueden ayudar a interactuar con la tecnología de hoy en día, y permite la comunicación con los clientes. Existen diversos dispositivos digitales que nos ayudan al manejo de estas herramientas, tales como, la computadora, tablets, smarthphones, y computadoras portátiles.

Dicho lo anterior estas herramientas facilitan el manejo de las redes sociales, softwares que han tenido alto impacto en el ámbito mercadológico. Ahora bien algunas de las herramientas digitales que podemos encontrar son las redes sociales las cuales según Vidal (2013) nos dice que pueden concebirse como una estructura social formada por individuos que están vinculados por algún motivo, ya sea amistad, parentesco, ideas, aficiones, relaciones de trabajo, docentes, etc. Para la caracterización de las redes sociales se establecen dos conceptos fundamentales: los nodos, que caracteriza a los individuos en la red y los enlaces o aristas, que vinculan a los individuos, pudiendo existir muchos tipos de enlaces entre los nodos. Se puede definir entonces que las redes sociales son formas de interacción social, definida como un intercambio dinámico entre personas, grupos e instituciones en contextos disimiles.
Constituye un sistema abierto, en construcción permanente, que involucra a personas que se identifican con las mismas necesidades y problemáticas y cuyos principios son el de crear, compartir y colaborar (Vidal, 2013). Las empresas han incrementado la publicidad en las redes digitales para dar a conocer sus marcas y/o servicios, por lo que en México esta táctica de mercadotecnia ha sido aceptada por los usuarios mexicanos, dándose la oportunidad de incrementar dicha actividad con mayor frecuencia. Las redes sociales son el principal motivo de los internautas mexicanos de entrar a Internet es por ello que las empresas visualizan un área de oportunidad para promorcionarse haciendo uso de ellas (Zavala, 2016).

Las herramientas de Internet están cambiando la forma de comunicarse entre las personas, cada día se incrementa el número de usuarios que se registran en alguna red social. En México se encuentran registrados los internautas en promedio en dos redes sociales, siendo las más utilizadas Facebook y Twitter de acuerdo con (AMIPCI, 2015) y no sólo estas redes son parte fundamental para la mercadotecnia, WhatsApp una de las herramientas esenciales para la comunicación entre los individuos, también usado para la publicidad de empresas de un modo más sencillo y directo con los clientes.

Existen otras herramientas fuera de las redes útiles para las empresas en su mercadotecnia tales como lo es Google ads siendo una herramienta esencial para la publicidad de una empresa. La publicidad ha resultado ser el medio de mejor funcionamiento para recaudar ingresos de una empresa y para ello Google AdWords y los servicios de AdSense podrían considerarse como un gran avance de la publicidad. AdWords Enfoca la publicidad con base en búsquedas realizadas por los usuarios. Por otro lado, AdSense permite mostrar anuncios adquiridos por Google en las páginas de otros editores Desde el punto de vista de Google, AdSense trae dinero de la llamada "larga" cola de la web69. Esto significa que el servicio se puede ofrecer a bajo costo también para pequeños jugadores, haciendo que la base potencial de clientes sea enorme Kangas (2007). 


\section{Marco referencial}

En El Instituto Nacional de Estadística y Geografía (INEGI) en colaboración con el Banco Nacional de Comercio y el otrora Instituto Nacional del Emprendedor realizaron la Encuesta Nacional de Productividad y Competitividad para las Micro, Pequeñas y Medianas Empresas ENAPROCE 2015 en la que menciona que del total de empresas consideradas, $97.6 \%$ son microempresas y concentran el $75.4 \%$ del personal ocupado total. Le siguen las empresas pequeñas, que son un $2 \%$ y tienen el $13.5 \%$ del personal ocupado.

Las medianas representan $0.4 \%$ de las unidades económicas y tienen poco más del $11 \%$ de los ocupados. De las micro empresas el $74.5 \%$ no cuentan con equipo cómputo por razones como falta de recursos, no la necesitan, no saben usarlos, entre otros, en el mismo sentido el $73.9 \%$ no tienen conectividad a internet por situaciones similares a las anteriores. Y de acuerdo a una investigación de Forbes nos dice que solo el 16\% de las PYMES invierte en tecnología y talento. En tanto las medianas empresas sólo presentan un $0.9 \%$ de inactividad en el uso de las tecnologías de información, el $99.1 \%$ de las empresas utiliza equipo de cómputo y el $98.4 \%$ usa internet (INEGI, 2015).

Dada la información que arroja el ENAPROCE y siendo que en la ciudad de Xalapa se encuentran un total de 1,798 (SECTUR, 2019) empresas medianas de servicios restauranteras se resalta la importancia de esta investigación.

\section{Métodología}

Para poder brindar un contexto que abarcara de forma eficaz los tópicos que se requerían medir, se llevó a cabo el proceso de operacionalización de la investigación, en la cual posterior a transitar de la conceptualización a la operacionalización, se encontraron en primera instancia la variable que se quiere medir que son las herramientas digitales en mercadotecnia, posterior a ello dos dimensiones, las cuales abarcan tres indicadores pertinentes y, por último, 17 ítems divididos en cada indicador para su medición.
Con base en cada una de ellas, se creó un instrumento fiable, avalado por 6 expertos en el tema, que arrojó la información necesaria para cuantificar los apartados y así obtener los posibles resultados, incluso, antes de aplicarlo a las empresas participantes, se tomó una muestra piloto (como más adelante se podrá observar), de manera que tuviéramos cálculos con la mayor precisión posible. La tabla 1 muestra el resultado de la operacionalización.

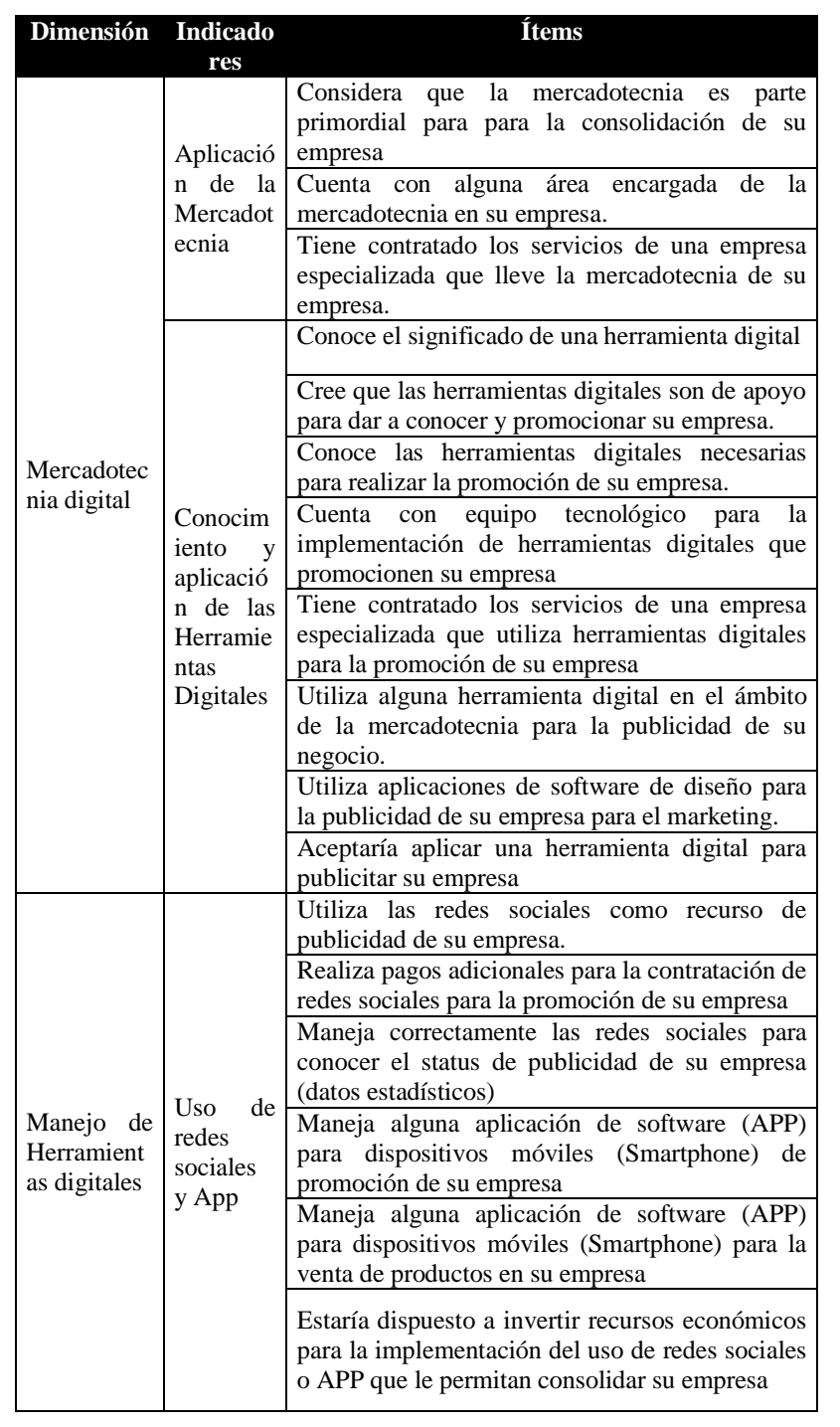

Tabla 1 División de las dimensiones, indicadores e ítems, resultado de la operacionalización

Fuente: Elaboración Propia (2019)

\section{Instrumento}

El juicio de expertos es un método de validación muy útil para verificar la fiabilidad de una investigación el cual según (Cabero y Llorente, 2013) citado por (Garrote y Rojas, 2015) este radica, en solicitar a una serie de personas la demanda de un juicio hacia un objeto, un instrumento, un material de enseñanza, o su opinión respecto a un aspecto concreto. 
Por ello, este método resulta de suma utilidad para las investigaciones cuantitativas. $\mathrm{La}$ selección de los jueces se llevó a cabo conforme a lo que plantea (Escobar y Cuervo, 2008), para ello se tomaron en cuenta la formación académica de los expertos, su experiencia y reconocimiento en la comunidad, además plantea un mínimo de cinco jueces, dos de los cuales deben ser expertos en medición y evaluación. Para cumplir con lo anterior, la validez de contenido se realizó a través del Juicio de Expertos (se envió a 7 expertos de los cuales contestaron 6). Se empleó el Coeficiente de Kappa de Fleiss. Fleiss (como se citó en Torres y Pereda, 2009) generalizó la aplicación del índice Kappa de Cohen para medir el acuerdo entre más de dos codificadores u observadores para datos de escala nominal y ordinal. Los valores obtenidos en el coeficiente de Kappa de Fleiss para cada criterio del instrumento evaluado por los expertos se muestran en la tabla 2.

\begin{tabular}{|l|l|l|l|}
\hline \multicolumn{1}{|l|}{ Suficiencia } & \multicolumn{1}{c|}{ Coherencia } & \multicolumn{1}{c|}{ Relevancia } & \multicolumn{1}{c|}{ Claridad } \\
\hline $\mathrm{K}=.47$ & $\mathrm{~K}=.69$ & $\mathrm{~K}=.64$ & $\mathrm{~K}=.50$ \\
\hline
\end{tabular}

Tabla 2 Coeficiente de Kappa de Fleiss obtenido Fuente: Elaboración Propia (2019)

\begin{tabular}{|r|l|}
\hline \multicolumn{2}{|c|}{ Interpretación del índice Kappa de Fleiss } \\
\hline Valor de K & Fuerza de concordancia \\
\hline $0.40-0.60$ & Regular \\
\hline $0.61-0.75$ & Buena \\
$>0.75$ & Excelente \\
\hline
\end{tabular}

Tabla 3 Interpretación del índice de Kappa de Fleiss Fuente: Fleiss (como se citó en Torres y Pereda (2009)

Por otro lado, Altman (como se citó en Torres y Pereda, 2009) propone una clasificación más extensa. Los coeficientes registran valores que van desde 0 a 1 , siendo 0 el valor donde hay mayor desacuerdo entre investigadores y 1 el punto donde encontramos mayor acuerdo. Su clasificación indica que los Kappas pueden ser Pobres (0 a 0.20), Débiles (0.21 a 0.40), Moderados (0.41 a 0.60), Buenos (0.61 a 0.80$)$ y Muy buenos (0.81 a 1.00), como se muestra en la tabla 5.

\begin{tabular}{|} 
Interpretación del Índice Kappa (Altman, 1991) \\
\hline Valor de K & Fuerza de concordancia \\
\hline$<0,20$ & Pobre \\
\hline $0,21-0,40$ & Débil \\
\hline $0,41-0,60$ & Moderada \\
\hline $0,61-0,80$ & Buena \\
\hline $0,81-1,00$ & Muy buena \\
\hline
\end{tabular}

Tabla 4 Interpretación del índice de Kappa de Fleiss de acuerdo Altman (1991)

Fuente: Elaboración propia (2019)
$\mathrm{Si}$ se toman los rangos de valores proporcionados en la tabla 4 , se puede concluir que las concordancias entre los criterios valorados por los jueces resultan: una fuerza de concordancia Buena para el criterio de Coherencia y Relevancia; una fuerza de concordancia Moderada para los criterios de Suficiencia y Claridad. Por lo expresado con anterioridad se cuenta con un instrumento fiable de acuerdo con los resultados de los coeficientes en la concordancia de los criterios valorados por los jueces. Posterior al juicio de expertos del instrumento se llevó a cabo el alpha de Cronbach, las tablas 4 y 5 representan la fiabilidad de la escala del instrumento obtenido de una encuesta piloto en la cual se realizó con un total de 30 elementos y 17 ítems, el cual tiene un valor de alfa de Cronbach de .806 lo que representa un valor del coeficiente alfa de Cronbach mayor a .8, y según George y Mallery (2003, p. 231). Por lo tanto el instrumento tiene una buena consistencia, y se puede aplicar.

\section{- $\quad$ Coeficiente alfa $>.9$ es excelente \\ - Coeficiente alfa $>.8$ es bueno \\ - $\quad$ Coeficiente alfa $>.7$ es aceptable \\ - $\quad$ Coeficiente alfa >.6 es cuestionable \\ - $\quad$ Coeficiente alfa $>.5$ es pobre \\ - $\quad$ Coeficiente alfa $<.5$ es inaceptable}

\begin{tabular}{|c|c|c|c|}
\hline \multicolumn{4}{|c|}{ Resumen del procesamien } \\
\hline \multirow{3}{*}{ Casos } & Válidos & 30 & 100 \\
\hline & Excluidos & 0 & .0 \\
\hline & Total & 20 & 100.0 \\
\hline
\end{tabular}

Tabla 5 Escala de todas las Variables

Fuente: Elaboración propia SPSS V. 21 (2019)

\begin{tabular}{|l|l|}
\hline \multicolumn{2}{|c|}{ Estadísticos de fiabilidad } \\
\hline Alfa de Cronbach & N de elementos \\
\hline .806 & 17 \\
\hline
\end{tabular}

Tabla 6 Resumen del procesamiento de 30 casos de las encuestas piloto

Fuente: Elaboración propia SPSS V. 21 (2019)

\section{Población y Muestra}

Para la determinación del tamaño de muestra se consideró una población de 1,798 restaurantes los cuales pertenecen al sector, medianas empresas en la ciudad de Xalapa. (SECTUR, 2019). 
Para ello Anderson, Sweeney y Williams (2008), nos citan "el tamaño de la muestra para una estimación de la proporción poblacional, para un muestreo estratificado se determina con la fórmula para población finita" (p. 933). Para el cálculo de la muestra se utilizó la fórmula para muestreo aleatorio simple estratificado, las medianas empresas del sector restaurantero

En donde:

$$
n=\frac{N p(1-p)}{N\left(\frac{E^{2}}{z_{\alpha / 2}^{2}}\right)+p(1-P)}
$$

$n=$ tamaño de la muestra

$z=$ nivel de confiabilidad $=\mathbf{9 5 \%}$

$p=$ de una encuesta piloto se determino $\mathbf{0 . 6 7}$

$N=$ tamaño de la población 1798

$E=$ error máximo $7 \%$

$n=\frac{1798(0.67)(1-0.67)}{1798\left(\frac{0.07^{2}}{1.96^{2}}\right)+((0.67)(1-0.67))}=\mathbf{1 5 8}$

$n=158$

Resultando una muestra de 158 encuestas para empresas restauranteras y de servicios.

\section{Resultados}

En el presente apartado se muestran los resultados más significativos con base en un análisis descriptivo de la información. En términos generales se podrá identificar que el tipo de empresas en estudio, 9 de cada 10 empresarios conocen las herramientas digitales que les permiten promocionarse, sin embargo solo 3 de cada 10 las utilizan lo que representa poco más del $30 \%$. Ahora bien de ese $30 \%$ que las utilizan el $86 \%$ lo hacen por medio de redes sociales dejando a un lado las herramientas digitales ad hoc para la mercadotecnia digital.

Un dato significativo es que 7 de cada 10 empresarios están dispuestos a invertir recursos económicos en herramientas digitales con el objetivo de consolidar su empresa, por lo que es un área de oportunidad para aquellas organizaciones que se dedican a la mercadotecnia haciendo uso de medios no convencionales, para posicionarse en el mercado al que pertenecen.

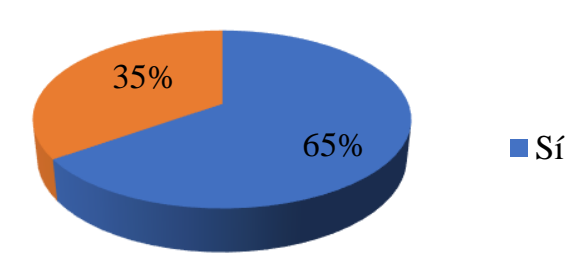

Gráfico 1 ¿Cuenta con alguna área encargada de la mercadotecnia en su empresa?

Fuente: Elaboración Propia (2019

En el Gráfico 1 se puede apreciar que el $65 \%$ de las empresas encuestadas cuentan con alguna área encargada de la mercadotecnia y el $35 \%$ respondió que no cuentan.

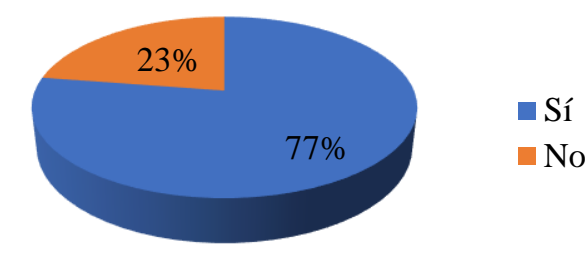

Gráfico 2 ¿Cree que las herramientas digitales en línea son de apoyo para dar a conocer y promocionar su empresa?

Fuente: Elaboración Propia (2019)

Como se visualiza en el Gráfico 2, el $77 \%$ de las empresas encuestadas respondieron que las herramientas digitales son de apoyo para dar a conocer y promocionar su empresa, solo el $23 \%$ respondió que no.

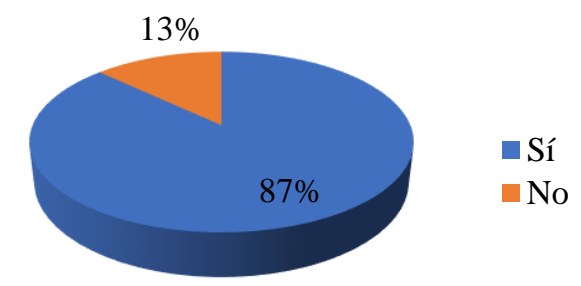

Gráfico 3 ¿Conoce las herramientas digitales en línea para realizar la promoción de su empresa?

Fuente: Elaboración Propia (2019)

El Gráfico 3 nos indica que el $87 \%$ de las empresas conocen las herramientas digitales que les permiten promocionar su empresa, y un 13\% respondió que no.

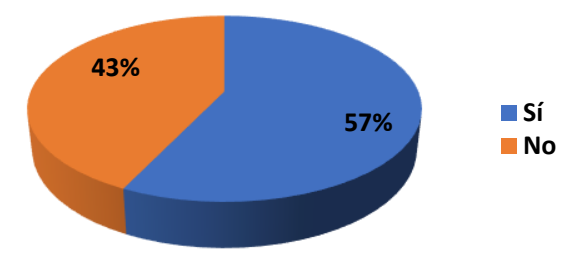

Gráfico 4. ¿Cuenta con equipo tecnológico para la implementación de herramientas digitales que promocionen su empresa?

Fuente: Elaboración Propia (2019)

GAZCA-HERRERA, Luis Alejandro, VALDEZ-MÉNDEZ, Alejandro, CULEBRO-CASTILLO, Karina y ALVAREZ-LOYA, Yamilet Sadaí. Análisis y propuesta de herramientas digitales aplicadas en la mercadotecnia en las medianas empresas de Servicios Restauranteras. Revista del Desarrollo Urbano y Sustentable. 2019. 
En el Gráfico 4 se puede visualizar que el $57 \%$ de las empresas cuentan con equipo tecnológico para la implementación de las herramientas digitales, el $43 \%$ no cuenta con equipo tecnológico.

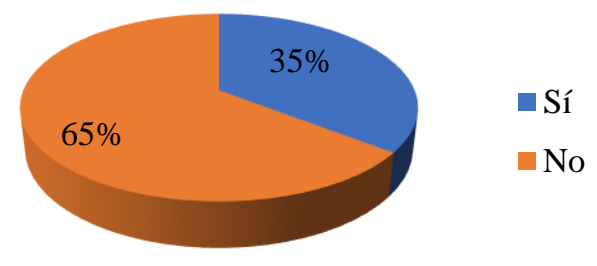

Gráfico 5 ¿Utiliza alguna herramienta digital en el ámbito de la mercadotecnia para la publicidad de su negocio?

Fuente: Elaboración Propia (2019)

En el Gráfico 5 se puede visualizar que sólo el $35 \%$ de las empresas utilizan alguna herramienta digital en el ámbito de la mercadotecnia para la publicidad de su negocio (no considerando a las redes sociales), el 65\% respondió que no las utiliza, esta pregutna es primordial ya que permitió dar respuesta a la hipótesis correspondiente cuyo resultado se muestra más adelante.

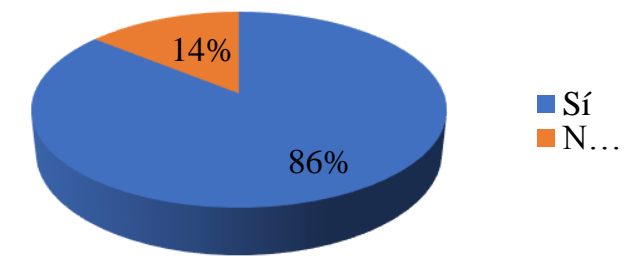

Gráfico 6 ¿Utiliza las redes sociales como recurso de publicidad de su empresa?

Fuente: Elaboración Propia (2019)

En el Gráfico 6 se puede apreciar que el $86 \%$ hacen uso de las redes sociales para la publicidad de la empresa, las redes sociales que utilizan son: Facebook, Twitter, Instagram, Whatsapp, entre otras. Un 14\% no hace uso de las redes sociales.

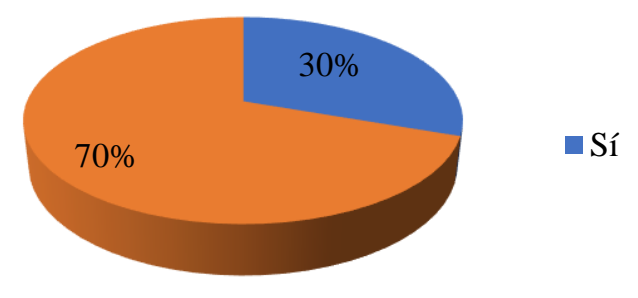

Gráfico 7 ¿Maneja alguna aplicación de software (APP) para dispositivos móviles (Smartphone) de promoción de su empresa?

Fuente: Elaboración Propia (2019)
En el Gráfico 7 se puede visualizar que solo el 30\% de las empresas hacen uso de aplicaciones de software o APP para la promoción de la empresa, entre estas están Uber eats, moto services, google empresas, $\mathrm{xl}$ monedero electrónico, pide click, canva, entre otros.

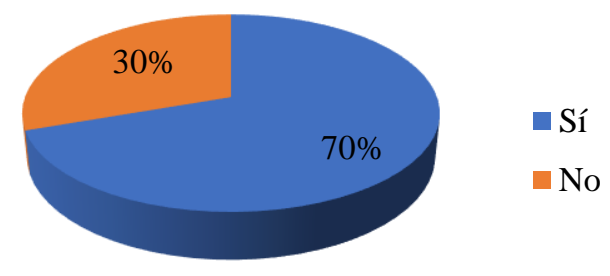

Gráfico 8 ¿Estaría dispuesto a invertir recursos económicos para la implementación del uso de redes sociales o APP que le permitan consolidar su empresa? Fuente: Elaboración Propia (2019)

En el gráfico 8 se puede apreciar que el $70 \%$ de las empresas están dispuestas a invertir recursos económicos para la implementación del uso de redes sociales o APP que les permitan consolidar su empresa en el mercado de los restaurantes, por lo que se visualiza un área de oportunidad para la mercadotecnia digital. Posterior a mostrar los resultados descriptivos de la investigación se realizó una prueba de hipótesis.

Test and CI for One Proportion: Utiliza alguna herramienta digital

Test of $p=0.3$ vs $p>0.3$

Event $=1=$ si

\begin{tabular}{|c|c|c|c|c|c|c|}
\hline Variable & $\mathbf{X}$ & $\mathbf{N}$ & $\underset{\mathbf{P}}{\text { Sample }}$ & $\begin{array}{l}95 \% \\
\text { Lower } \\
\text { Bound }\end{array}$ & $\begin{array}{c}\text { Z- } \\
\text { Value }\end{array}$ & $\begin{array}{c}\text { P- } \\
\text { Value }\end{array}$ \\
\hline $\begin{array}{l}\text { Utiliza alguna } \\
\text { HD }\end{array}$ & \begin{tabular}{|l}
5 \\
5 \\
\end{tabular} & $\begin{array}{l}15 \\
5\end{array}$ & 0.3548 & 0.2916 & 1.49 & 0.068 \\
\hline
\end{tabular}

Tabla 7 Prueba de hipótesis

Fuente: Elaboración Propia Minitab V. 14 (2019)

En esta prueba como el valor del Pvalue es mayor al nivel de significancia de 0.05 utilizado en la prueba, no se debe rechazar la hipótesis nula, y se puede concluir que no más el 30\% de todas las empresas de servicio de restauranteras, utilizan alguna herramienta digital en el ámbito de la mercadotecnia para la publicidad de su negocio, lo que quiere decir que se debe buscar herramientas digitales como apoyo en la publicidad del mercado para estos negocios para consolidar su posición. 


\section{Propuesta}

Gerrikagoitia, et al., (2014) plantea que, de manera similar a las ventas reales, el proceso de venta basado en el comercio electrónico debe estar en concordancia con las necesidades del cliente; antes, durante y después de la venta, esto requiere un conocimiento preciso de las preferencias del cliente. Wong y Yazdanifard (2015) definen el marketing de contenido como una manera de informar y persuadir a la audiencia con contenido sólido para crear conciencia o cambiar su percepción sobre una marca. Plantean que un mejor contenido puede motivar a los clientes a comprar bienes o servicios, transformarlos en clientes leales e incluso que difundan el mensaje a otros.

Echeverría (2016) considera al eMarketplace como una estrategia de marketing digital muy importante en los tiempos actuales, donde internet se ha convertido en el medio de comunicación más usado a nivel mundial.

Actualmente las organizaciones no tratan de influenciar a los consumidores, sino que desarrollan programas de mercadeo influenciados por estos (Jain, 2014). Jain (2014) demuestra la estrecha relación que existe entre el comportamiento del consumidor y el marketing digital. Y esto nos lleva al uso de las redes sociales. Las cuales crecen de una forma mucho más acelerada que cualquier otra plataforma de internet como lo son: WhatsApp, Facebook, Messenger, Instagram o las plataformas de comercio de imágenes como Snapchat. En las redes sociales, el objetivo no es vender el producto o el servicio, la meta es formar una comunidad de usuarios con una conexión e identificación con la marca. Y como bien sabemos las redes sociales se han vuelto de vital importancia para la mercadotecnia sin embargo no son las únicas herramientas digitales que se pueden utilizar ya sea para la exhibición de publicidad o para la creación de esta.

Como resultado de la investigación el $85 \%$ de las empresas encuestadas hacen uso de las redes sociales como herramienta digital, es por ello que a continuación se muestran algunas de las herramientas que no son parte de ellas y que son aplicables para la mercadotecnia.
Google Analytics. Esta herramienta gratuita de analítica web es fundamental para medir el tráfico de visitas, y analizar el comportamiento de los usuarios cuando visitan los contenidos. (analytics.google.com, 2019)

Search Console. Es un servicio gratuito ofrecido por el buscador de Google que ayuda a supervisar y mantener la presencia del sitio web en los resultados de búsquedas. (search-console, s.f.)

Keyword Planner. Es una herramienta gratuita que te ayuda a planificar los anuncios de Google Adwords, se puede utilizar sin necesidad de invertir en publicidad. Sin embargo, es necesario que se tenga una cuenta de correo Gmail. En esta aplicación pueden buscar ideas de palabras claves para posicionar mejor los contenidos en el sitio web, y así conseguir optimizar el posicionamiento en los resultados búsquedas para captar mayor tráfico de visitas. (google-ads, 2019).

Picktochart. Es otra herramienta para marketing de contenidos, ya que permite diseñar y crear infografías sin necesidad de tener conocimientos técnicos como un diseñador gráfico. La versión gratuita de esta herramienta de marketing digital tiene ciertas limitaciones, puede utilizar numerosas plantillas prediseñadas y elementos para las infografías.

Scribus. Es un programa de maquetación gratuito, libre y multiplataforma. Con esta aplicación se podrán crear desde revistas, carteles, boletines de noticias, infografías. Todo ello en distintos formatos, pudiendo utilizar plantillas, ya incorporadas, o creando todo desde cero. Ofrece soporte técnico. (scribus.net, 2016)

Flipboard. Con Flipboard se puede crear una propia revista digital totalmente personalizada. Esta herramienta te permite escoger las temáticas de las noticias que se quieran leer, así como las correspondientes categorías y subcategorías. De esa forma, será más sencillo compartir los contenidos en las redes sociales. (flipboard.com, 2019) 
Buffer. La versión gratuita de Buffer permite programar y gestionar las publicaciones en LinkedIn, Twitter, Facebook y una página de Google+, así como añadir vídeos o fotos alternativas a las publicaciones compartidas. Además, te indica los horarios óptimos en los que compartir un determinado contenido. (buffer.com, 2019).

Todas las empresas están en constante cambio debido al entorno que las rodea, el cual evoluciona día con día, y para poder seguir en el mercado es necesario que se adapten a los nuevos requerimientos expuestos por los cambios tecnológicos y la forma en la que la sociedad interactúa con ellos. Por esto es necesario que abran su panorama en cuanto a la mercadotecnia digital, lo que les proporcionará una ventaja competitiva y le abrirá mejores oportunidades de crecimiento y aceptación del cliente.

\section{Conclusiones}

Tomando en cuenta que el departamento de mercadotecnia es indispensable para una organización, y considerando la importancia en cuanto a imagen y promoción de productos, así como para comercialización, resulta relevante la claridad con que esta área debe trabajar en paralelo a la empresa, teniendo claro los métodos de innovación que se deben poner en práctica para buscar un incremento sustancial en el mercado y que su producto logre potencializarse al máximo.

El objetivo fundamental de esta investigación fue realizar una evaluación a la percepción del empresario sobre herramientas aplicadas a la mercadotecnia para el crecimiento de la empresa, conociendo el número de restaurantes que utilizan las herramientas digitales, abordando así, cuáles y cuantas, herramientas digitales conocen y utilizan las medianas empresas del sector restaurantero en la ciudad de Xalapa, Veracruz, asimismo, la aportación de otras herramientas digitales que pueden ser de ayuda para estas empresas en cuestión de su publicidad.

Siendo así, la aportación principal de este articulo consistió en la recolección y análisis de datos que nos proporcionaron las empresas sobre la implementación de estas herramientas digitales dentro de sus organizaciones.
Esto por medio de una investigación de carácter cualitativo, posteriormente pasando a estudio de campo con la realización de encuestas a estas empresas. Arrojándonos como resultado que la mayoría de las empresas del sector restaurantero no utilizan adecuadamente las herramientas digitales de marketing o las desconocen por completo, siendo que más del $80 \%$ de estas solo enfocan su publicidad únicamente en redes sociales como Facebook, Instagram, Twitter, etc.

Por ende, podemos confirmar la hipótesis anteriormente establecida en este documento en las que se afirmó que las empresas de sector restaurantero de Xalapa, Veracruz no utilizan las herramientas digitales de marketing que no sean redes sociales, dejando un área de oportunidad para promocionarse con aplicaciones que son ad hoc para la mercadotecnia digital, lo que puede originar que no se consoliden, que no tengan un crecimiento y no estén posicionadas en el área de alimentos en las que están inmersas.

Para concluir; las medianas empresas del sector restaurantero de la ciudad de Xalapa necesitan expandir su uso de herramientas digitales fuera de las redes sociales para que, a largo plazo logren llegar a mayor número de potenciales clientes. De igual manera, se hace propuesta de aplicaciones de diseño gráfico para la publicidad de las empresas, como son Piktochart, Flipboard, y Scribus ya que, en los resultados obtenidos observamos que la única aplicación utilizada es Canva, siendo una aplicación con menor dificultad de manejo.

Con esta propuesta se invita a las empresas a expandir el uso de softwares para una mejora de resultados en cuestión de diseño $y$, obtengan una mayor audiencia entre sus clientes, logren ser ubicados y, por ende, tengan un mayor número de ventas. Finalmente deben aplicar en el uso de las herramientas digitales actuales como son uber eat, sin delantal, rappi, postmates, entre otras para consolidarse en el mercado con clientes que hacen uso de estas aplicaciones, lo cual les permite incrementar sus ventas y posicionarse en el mercado. 


\section{Referencias}

Aiken, Lewis (2003). Test psicológicos y evaluación. México: Pearson Education Cabero Almenara, J. y Llorente Cejudo, M. C. (2013), La aplicación del juicio de experto como técnica de evaluación de las tecnologías de la información (TIC). En Eduweb. Revista de Tecnología de Información y Comunicación en Educación, 7 (2) pp.11-22. Recuperado de: http://tecnologiaedu.us.es/tecnoedu/images/stori es/jca107.pdf

Apak, S. y Etay, E. (2014). Global innovation and Knowledge Management Practice in Small and Medium Enterprises (SMEs) in Turkey and the Balkans. Procedia, Social and Behavioral Sciences, 150, pp. 1260-1266.

AMIPCI. (2015, 1 enero). Estudio de comercio electrónico. Recuperado 1 enero, 2015, de https://amipci.org.mx/estudios/comercio_electr onico/Estudio_de_Comercio_Electronico_AMI PCI_2015_version_publica.pdf

Buffer. (2019, 1 enero). Buffer. Recuperado 1 enero, 2019, de https://buffer.com/

Chaffey, D. (2015) Managing Digital Marketing in 2015. Smart Insights. Recuperado de smartinsights.com/guides/managingdigitalmarketing-2015/

Chaffey, D. y Smith, P. R. (2013). E-marketing eXcellence: Planning and Optimizing your Digital Marketing. Routledge.

Cedeño, R. M. (2017, 31 octubre). Observaciones acerca de los dispositivos móviles. Recuperado 4 octubre, 2017, de https://dialnet.unirioja.es/servlet/articulo?codig $\mathrm{o}=6155633$

Escobar, J., \& Cuervo, Á. (2008). Validez de contenido y juicio de expertos: una aproximación a su utilización. Avances En Medición. Recuperado de: http://doi.org/10.1016/j.eatbeh.2007.10.005

EP, B. N. (2017, 20 junio). Herramientas digitales. Recuperado 4 noviembre, 2017, de https://docs.google.com/document/d/1HPLGyfb g9XbygQChUcRkAO0OiSub0LvhHnqDKxgZ $\mathrm{K} 5 \mathrm{~g} / \mathrm{edit}$ ?pli=1\#
Flipboard. (2019, 1 enero). Flipboard. Recuperado 1 enero, 2019, de https://flipboard.com/

George, D. y Mallery, P. (2003). spss for Windows step by step: A Simple Guide and Reference. 11.0 Update (4. ${ }^{\mathrm{a}}$ ed.). Boston: Allyn \& Bacon.

Google ads. (2019, 1 enero). Google ads. Recuperado 1 enero, 2019, de https://support.google.com/googleads/answer/7337243?hl=en

Garrote, P., y Rojas (2015), M. La validación por juicio de expertos: dos investigaciones cualitativas en Lingüística aplicada. Revista Nebrija. Recuperado de https://www.researchgate.net/publication/27495 1988_La_validacion_por_juicio_de_expertos_d os_investigaciones_cualitativas_en_Linguistica _Aplicada_Validation_by_expert_judgements_t wo_cases_of_qualitative_research_in_Applied_ Linguistics

Google Analytics. (2019a, 1 enero). Google Analytics. Recuperado 1 enero, 2019, de https://analytics.google.com/analytics/web/prov ision/?authuser $=0 \# /$ provision

Google Seach Console. (2019, 1 enero). Google Seach Console. Recuperado 1 enero, 2019, de https://search.google.com/search-

console/about?hl=es\&utm_source=wmx\&utm_ medium $=$ wmx-welcom

Gutiérrez-Leefmans, C., \& Nava-Rogel, R. (2016). Mercadotecnia digital y las pequeñas y medianas empresas: revisión de la literatura.Enl@ce: Revista Venezolana de Información, Tecnología y Conocimiento, 13 (1), 45-61.

Kiinteroo, H (2017), Herraminetas digitales ¿qué son? Recuperado el 6 de febrero 2019, https://www.scribd.com/document/222872685/ HERRAMIENTASDIGITALES-docx

Instituto de Estadística y Geografía. (2015, 1 julio). Encuesta Nacional sobre Productividad y Competitividad de las Micro, Pequeñas y Medianas Empresas. Recuperado 1 julio, 2015, de

https://www.inegi.org.mx/contenidos/programa s/enaproce/2015/doc/ENAPROCE_15.pdf 
Kangas, P., Toivonen, S., \& Back, A. (2007b, 1 abril). Ads by Google and other social media business models. Recuperado 1 abril, 2007, de https://www.vtt.fi/inf/pdf/tiedotteet/2007/T2384 .pdf

Miranda Zavala, Ana María, \& Cruz Estrada, Isaac. (2016). Redes sociales: herramienta de marketing internacional en el sector hotelero. El periplo sustentable, (31), 00012. Recuperado en 20 de junio de 2019, de http://www.scielo.org.mx/scielo.php?script=sci _arttext\&pid=S1870-

90362016000200012\&lng=es\&tlng=es.

Nada, N. et al. (2012), Innovation and knowledge management practice in Turkish SMEs, Journal of Knowledge Management, Economics and Information Technology, II(1), pp.248-265.

On line Kappa Calculator: http://justusrandolph.net/kappa/

Perdigón Llanes, Rudibel, Viltres Sala, Hubert, \& Madrigal Leiva, Ivis Rosa. (2018). Estrategias de comercio electrónico y marketing digital para pequeñas y medianas empresas. Revista Cubana de Ciencias Informáticas, 12(3), 192-208. Recuperado en 20 de junio de 2019, de http://scielo.sld.cu/scielo.php?script=sci_arttext \&pid=S2227-

$18992018000300014 \& \operatorname{lng}=$ es\&tlng=es.

Piktochart. (2019, 1 enero). Piktochart. Recuperado 1 enero, 2019, de https://piktochart.com/

Ramos, J. J. (2015, 1 enero). Marketing con Whatsapp. Recuperado 1 enero, 2015, de https://books.google.com.mx/books?hl=es\&lr= \&id=LTr9CwAAQBAJ\&oi=fnd\&pg=PT2\&dq $=$ Marketing + con + WhatsApp\&ots=qqqNg6huo M\&sig=k0M4NoaQHluhx1saZO3-

HMunH9Y\#v=onepage\&q=Marketing\%20con $\%$ 20WhatsApp\&f=false

Scribus. (2016, 1 enero). Scribus. Recuperado 1 enero, 2016, de https://www.scribus.net/

Secretaría de turismo y cultura SECTUR. (2019). Prestadores de servicios. Recuperado 1 enero, 2019, de https://veracruz.mx/restaurantes.php?Municipio $=87$
Sparrow, J. (2001). Knowledge Management in Small Firms, Knowledge and Process Management, 8(1), 3-16

Torres, J.J. y Pereda, V.H. (2009). Cálculo de la fiabilidad y concordancia entre codificadores de un sistema de Categorías para el estudio del foro online en e-learning 27, 89-104.

Vidal Ledo, María, Vialart Vidal, María Niurka, \& Hernández García, Luis. (2013). Redes sociales. Educación Médica Superior, 27(1), 146-157. Recuperado en 20 de junio de 2019, de http://scielo.sld.cu/scielo.php?script=sci_arttext \&pid=S0864$21412013000100017 \& \operatorname{lng}=$ es\&tlng=es.
GAZCA-HERRERA, Luis Alejandro, VALDEZ-MÉNDEZ, Alejandro, CULEBRO-CASTILLO, Karina y ALVAREZ-LOYA, Yamilet Sadaí. Análisis y propuesta de herramientas digitales aplicadas en la mercadotecnia en las medianas empresas de Servicios Restauranteras. Revista del Desarrollo Urbano y Sustentable. 2019. 